Anales de Geografía de la Universidad Complutense ISSN: 0211-9803

http://dx.doi.org/10.5209/AGUC. 62487

\title{
Gobernabilidad territorial y relaciones de poder en espacios turísticos: los conflictos derivados de las políticas públicas de renovación de los destinos turísticos consolidados de litoral ${ }^{1}$
}

\author{
Moisés Simancas $\mathrm{Cruz}^{2}$ \\ Recibido: 13 de mayo del 2017/ Enviado a evaluar: 21 demayo del 2017/ Aceptado: 18 de octubre del 2018
}

Resumen. Las acciones y procesos de renovación se revelan como claves para el reposicionamiento competitivo de las áreas turísticas consolidadas. Sin embargo, su implementación genera conflictos. Ello se debe a los intereses, objetivos y lógicas de funcionamiento divergentes y contrapuestos de los distintos y diversos actores, públicos y privados. El objetivo de este trabajo es analizar el conflicto derivado de la implementación de la estrategia de la política pública del destino turístico Islas Canarias (España) de vincular la autorización de la construcción de nuevos establecimientos de alojamiento turístico de cuatro estrellas a la renovación de existentes. Se ha optado por el enfoque de análisis de contenido o de correlato, de modo que el sujeto de observación de la investigación ha sido el proceso mismo y sus diversos momentos temporales, profundizando en el conjunto de elementos estructurales que han conformado el conflicto: causas, componentes, actores objetivos y efectos.

Palabras clave: alojamiento turístico; conflicto; política pública; gobernabilidad; renovación.

\section{[en] Territorial governance and power relations in tourist areas: the conflicts derived from the public policies of renewal of consolidated tourist destinations on the coast}

\begin{abstract}
The actions and processes of renewal are revealed as key to the competitive repositioning of the consolidated tourist areas. However, its implementation generates conflicts. This is due to divergent interests, objectives and logics of operation of the public and private actors. The objective of this paper is to analyze the conflict derived with the strategy of public policy of the tourist destination Islas Canarias (Spain) to link the authorization of the construction of new tourist establishments to the renovation of
\end{abstract}

1 La investigación que da lugar a este trabajo se inscribe en el proyecto titulado "Crisis y reestructuración de los espacios turísticos del litoral español" (CSO2015-64468-P) del Ministerio de Economía y Competitividad (MINECO). Asimismo, constituye uno de los resultados del proyecto "Tecnologías de Información Geográfica aplicadas al análisis y diseño de propuestas innovadoras para la renovación de los alojamientos turísticos", financiado por la Fundación CajaCanarias.

2 Departamento de Geografía e Historia. Universidad de La Laguna.

E-mail: msimancas@ull.edu.es 
existing ones. The content analysis or correlate approach has been chosen, so that the subject of research observation has been the process itself and its various temporal moments. It delves in the structural elements that have shaped the conflict (causes, Components, target actors and or effects).

Keywords: tourist accommodation; conflict; public policy; governability; renovation.

[fr] Gouvernance territoriale et relations de pouvoir dans les zones touristiques: les conflits issus des politiques publiques de renouvellement des destinations touristiques consolidées du littoral

Résumé. Les actions et les processus de renouvellement sont révélés comme la clé du repositionnement concurrentiel des zones touristiques consolidés. Cependant, sa mise en œuvre crée des conflits. En effet, les intérêts, les objectifs et les logiques de fonctionnement divergentes et contrastées des différents et les diverses parties prenantes, publiques et privées. Le but de cet article est d'analyser le litige découlant de la mise en œuvre de la stratégie de destination touristique de la politique publique Îles Canaries (Espagne) pour relier l'autorisation de la construction de nouveaux établissements d'hébergement touristique quatre étoiles la rénovation de ceux qui existent déjà. Il a été choisi de concentrer l'analyse du contenu ou de corrélation, de sorte que l'objet de recherches d'observation a été le processus lui-même et de ses différents points de temps, l'approfondissement de l'ensemble des éléments structurels qui ont fait l'origine du conflit, composants, effets objectifs et acteurs.

Mots clés: hébergement touristique; les conflits; la gouvernance; politiques publiques; renouvellement.

Cómo citar. Simancas Cruz, M. (2018): Gobernabilidad territorial y relaciones de poder en espacios turísticos: los conflictos derivados de las políticas públicas de renovación de los destinos turísticos consolidados de litoral. Anales de Geografia de la Universidad Complutense, 38(2), 435-460.

Sumario. 1. Introducción. Las políticas públicas de renovación en la generación de conflictos entre actores en los espacios turísticos. 2. El conflicto generado por la estrategia de renovación de alojamientos obsoletos de Canarias. 2.1. El origen del conflicto: la decisión pública de condicionar la construcción de nuevos hoteles de cuatro estrellas a la renovación de los establecimientos de alojamiento turístico obsoletos. 2.2. El nudo del conflicto: la judicialización de la estrategia. 2.3. El desenlace del conflicto: la flexibilización de la estrategia. 3. Conclusiones. 4. Bibliografía.

\section{Introducción. Las políticas públicas de renovación en la generación de conflictos entre actores en los espacios turísticos}

Aunque la actividad turística se sustenta fundamentalmente en el sector privado, constituye uno de los campos de negocio en el que el empresariado no sólo es partidario de cierto intervencionismo público, sino que, incluso, lo exige en momentos puntuales y contracíclicos (Francisco, 2003), en relación con servicios e infraestructuras, generales y turísticas, así como en función de sus legítimos objetivos o del conjunto de fallos del mercado. Por tanto, no existe alternativa respecto a la intervención de la Administración Pública en la actividad turística; el debate radica en definir los límites e intensidades de esa intervención (Merinero y Pulido, 2009). Ello dota de poder a la política pública turística $\mathrm{y}$, por ende, a la Administración competente. 
Lo anterior determina que la gobernabilidad del turismo, entendida como un atributo del arte de gobernar, incide en la capacidad del sistema político para generar confianza (Velasco, 2008), tanto dando respuesta a la demanda de los actores (individuos, grupos $\mathrm{u}$ organizaciones) presentes en cada espacio turístico, como regulando los posibles conflictos a través de la adopción de soluciones eficaces y en igualdad de condiciones. Por tanto, cualquier política turística supone un ejercicio de poder, en cuanto define las condiciones sistémicas e institucionales bajo las cuales éste se ejerce y es asumido por las partes interesadas (stakeholder). De esta manera, la capacidad de los actores públicos para intervenir en las decisiones colectivas de manera legítima, utilizando su influencia y autoridad. Por consiguiente, el "poder" no sólo se refiere a la capacidad de tales actores para promover sus intereses, sino también al papel de las estructuras políticas e institucionales (Bassols, 2011).

Por otra parte, siguiendo el proceso secuencial de generación-degeneraciónregeneración de un destino turístico —o de un área turística dentro del mismocalificable como "maduro", "consolidado", "estancado", "saturado", "pionero", "con experiencia", "en la etapa final de crecimiento" o de manera similar según la terminología de los distintos modelos evolutivos, cualquier política pública de renovación constituye el elemento superior de la cadena de toma de decisiones dirigidas a su reposicionamiento competitivo. Como apuntan Vera et al (2013), la renovación turística debe afrontarse, entre otras cuestiones, concediendo especial importancia a los agentes sociales, tanto desde el punto de vista de la percepción del destino, como de la identificación de las necesidades y las prioridades, donde todos deben tener beneficios y responsabilidades. A su vez, como señala Antón (2011:36). "el éxito de las acciones de renovación radica, en todo caso, en la existencia de una visión estratégica sobre cada destino que implique el consenso político, empresarial $y$ social". De esta manera, la propia naturaleza de cualquier política pública de renovación de un espacio turístico la convierte, al menos en teoría, en un ámbito especialmente interesante para observar el concepto de "gobernanza". En coherencia con lo planteado por Duran (2013), ésta supone un estilo de gobierno, que se caracteriza por más interacción y cooperación entre la pluralidad de actores presentes en el territorio que participan en la formulación de las políticas públicas (Ledesma, 2016). Así, la gobernanza se plantea como una herramienta analítica y operativa para avanzar en la gobernabilidad territorial del turismo. Ello se debe a que permite aplicar un enfoque de abajo a arriba (bottom-up), articulado en torno a un proceso permanente y cooperativo de implicación, diálogo intenso y continuo, acuerdo y consenso entre la pluralidad y diversidad de stakeholders. Debe posibilitar un funcionamiento y una visión coordinada, compartida y trasparente en los procesos de adopción de las estrategias de planificación y gestión de las áreas turísticas (nivel estructural), con el fin de crear tanto las condiciones para que éstas sean reconocidas y asumidas (legitimidad) por la colectividad, como los escenarios de negociación, compromiso y concertación entre el objetivo político-técnico y los múltiples y diversos intereses y expectativas de los actores estratégicos implicados (nivel intencional). Esta forma de diseño e implementación de las políticas públicas de renovación de las áreas turísticas la aproxima a procesos de empoderamiento, es decir, 
el derecho a participar y la legitimidad en la toma de decisiones hacia la equidad de poder, en coherencia con lo planteado, entre otros, por Jamal y Getz $(1995,1999)$, Selin y Chávez (1995), Reed (1999), Robinson (1999), De Araujo y Bramwell (2002) y Timothy (2007) para elucidar los procesos de colaboración en el contexto del desarrollo turístico. Por consiguiente, la gobernanza turística aporta los procesos de decisión público-privados que van a mejorar la gestión de los conflictos que inevitablemente provoca la actividad en el destino (Velasco, 2008).

Sin embargo, la gobernanza turística se está planteando, en los pocos casos llevados a la práctica, más como un concepto de discutible procedencia y dudosa intención (Farinós, 2008), una mera declaración de intenciones planteada desde diversos enfoques teóricos o una metodología de trabajo, que como un proceso real, aplicado y con resultados concretos y mensurables. Ello se complica por la habitual falta de coordinación y de cooperación entre los distintos niveles planteada, entre otros, por Farinós et al. (2005) y Romero (2009). Ambas cuestiones explican que la gobernabilidad del turismo suele fundamentarse en imposiciones normativas descendentes (top-down), que se enmarcan en paradigmas estáticos, a modo de sistema cerrado, sin retroalimentación (positiva o negativa), con preeminencia de explicaciones lineales del tipo causa-efecto y, en el mejor de los casos, de la unidireccional procedente de la información pública o discusión parlamentaria.

Una de las consecuencias inmediatas de lo anterior es la aparición de dos tipos de actores privados en los procesos de aplicación de las políticas públicas de renovación de las áreas turísticas. Por un lado, las partes interesadas, que, aunque son relevantes, no pueden intervenir en el proceso de toma de decisiones para "hacer valer" sus intereses, al carecer del poder necesario; ello explica su rechazo a la correspondiente política pública. Por otro, un "grupo privilegiado", que, a modo de definitive stakeholders (Mitchell et al., 1997), constituye una minoría o élite, que se organiza para resguardar sus intereses, ejerciendo su capacidad (poder) para influir de forma sustancial en los resultados de la política, al aprovechar los tres atributos considerados básicos para cualquier parte interesada (Mitchell et al., 1997): a) su capacidad para influir desde su parcela de poder, definiendo sus reglas y fijando restricciones para la participación de otros actores; b) la legitimidad de las relaciones; y c) la urgencia de sus demandas.

El control de estos definitive stakeholders propicia la existencia de estructuras estratificadas en la red de actores privados. Ello implica procesos de exclusión y subordinación de actores, generándose dos tipos de relaciones entre los mismos. Por un lado, las relaciones asimétricas y desiguales, debido a la pluralidad y heterogeneidad de posiciones, objetivos, intereses y lógicas de funcionamiento; considerando la geometría del poder (Massey, 1994), éstas hacen que los actores se diferencien entre "ganadores" y "perdedores". Por otro lado, las relaciones de dominio-dependencia - y, por tanto, de subordinación-; éstas provocan tensiones, desacuerdos, controversias e interacciones antagónicas cuando los "dominados" no cumplen con la exigencia de obediencia de las imposiciones de los actores privilegiados (“dominadores"). 
Estas relaciones crean un escenario de rivalidad, incompatibilidad o disfuncionalidad entre los actores, dando lugar a conflictos. El conocimiento de los motivos que los originan y, sobre todo, de los intereses divergentes de los actores, resulta una tarea imprescindible para entenderlos $\mathrm{y}$, por ende, gestionarlos $\mathrm{y}$ solucionarlos, o cuanto menos, mitigarlos. Lo mismo sucede con las dinámicas relacionales o geometrías del poder, en cuanto la identificación de vínculos, relaciones y patrones de interacción entre los actores ayuda a explicar la configuración y el desarrollo territorial del turismo y, por tanto, el correspondiente modelo de desarrollo turístico (Massey, 2009), como ponen de manifiesto los trabajos académicos orientados a la identificación del papel que desempeñan y la clasificación de los stakeholders turísticos, entre los que destacamos los de Jamal y Getz (1995), Selin y Chavez (1995), Reed (1997), Sautter y Leisen (1999), Caffyn y Jobbins (2003), Merinero y Pulido, 2009; Bornhorst, Ritchie y Sheehan (2010), Bramwell, 2011; Ledesma, 2012). Asimismo, en la medida en que el poder no solamente debe referirse a la capacidad de los actores para promover sus intereses, sino también al papel que juegan las estructuras políticas e institucionales, la identificación de aquéllos capaces de controlar la agenda y el discurso político resulta una cuestión relevante (Lukes, 1985); ello explica su tratamiento recurrente en trabajos académicos que vinculan el enfoque de las relaciones entre los diversos actores y niveles administrativos con la gobernanza y el turismo (Hall, 1999 y 2011; Aas et al., 2005; Dredge, 2006; Baggio, 2008; Dredge y Pfforr, 2008; Baggio et al., 2011; Beaumont y Dredge, 2010; Ruhanen et al., 2010; Beritelli, 2011; Bramwell y Lane, 2011; Richins et al., 2011; Scott et al., 2011; Bramwell, 2013; Vázquez, 2014; Velasco, 2014; Queiroz y Rastrollo-Horrillo, 2015).

El objetivo principal de este trabajo es analizar los conflictos entre actores generados por la implementación de políticas públicas de renovación de espacios turísticos consolidados de litoral. Con el fin de aportar algo de contenido empírico no especulativo-, así como dotar de una dimensión aplicada a los diferentes enunciados generales, nos basamos en el conflicto derivado de la estrategia de renovación del destino Islas Canarias (España) de vincular la autorización de la construcción de nuevos establecimientos de alojamiento turístico de cuatro estrellas a la renovación edificatoria de los existentes. Se pretende indagar los antagonismos, las confrontaciones y las divergencias de intereses, objetivos y racionalidades. Para ello, en la medida en que el devenir de cualquier conflicto es un proceso que implica acciones y reacciones, se ha optado por el enfoque de análisis de contenido o de correlato, de modo que el sujeto de observación de la investigación ha sido el proceso mismo y sus diversos momentos temporales, profundizando en el conjunto de elementos estructurales que han conformado el conflicto (causas, componentes, actores, objetivos y acciones). 


\section{El conflicto generado por la estrategia de renovación de alojamientos obsole- tos de Canarias}

\subsection{El origen del conflicto: la decisión pública de condicionar la construcción de nuevos hoteles de cuatro estrellas a la renovación de los establecimientos de alojamiento turístico obsoletos}

Las Islas Canarias constituyen unos de los principales destinos europeos de turismo vacacional, especializado en el producto "sol y playa"; prueba de ello es que, según el Instituto Canario de Estadística, recibió 14.981.113 turistas en 2016, que se concentraron fundamentalmente en las cuatro islas consolidadas turísticamente (Tenerife, Gran Canaria, Fuerteventura y Lanzarote) del Archipiélago. Su actual modelo turístico alojativo es resultado, en gran medida, de la política turística denominada comúnmente como "moratoria turística", iniciada en 2001. Insertada en un proceso de gobierno del turismo desde su ordenación territorial $-\mathrm{y}$, por tanto, en un intervencionismo reglamentista en lugar de una desregulación liberalizadora-, la renovación de los alojamientos turísticos se ha impulsado durante su tercera etapa en virtud de las Leyes 6/2009, de 6 de mayo, de medidas urgentes en materia de ordenación territorial para la dinamización sectorial y la ordenación del turismo, que modificó parcialmente la 19/2003, de 14 de abril, por la que se aprueban las Directrices de Ordenación General y las Directrices de Ordenación del Turismo de Canarias, siendo sustituida, a su vez, por la 2/2013, de 29 de mayo, de Renovación y Modernización Turística de Canarias.

Esta trascendencia otorgada a la renovación de los alojamientos turísticos resulta lógica y relevante si consideramos que el Informe de Evaluación de la Ley 2/2013, elaborado por el Gobierno de Canarias en octubre de 2014, estimó que el $67,1 \%$ de las 371.177 plazas turísticas (hoteleras y extra-hoteleras) que en ese momento estaban autorizadas en el Archipiélago debían someterse, en mayor o menor medida, a intervenciones edificatorias que, trascendiendo las actuaciones de rehabilitación física, que comprende la obra menor o de estricto mantenimiento y ornato (conservación), implicasen una modernización y, sobre todo, una "reinvención" del alojamiento (física, conceptual, funcional, etc.). Esta situación se complica si consideramos que solo 35.570 plazas de ellas (el 14\%) habían iniciado el procedimiento administrativo para su renovación.

Las normas que articulan esta última etapa de la moratoria turística han reducido la trascendencia de la medida de "crecimiento cero" de su primera y segunda etapa (Simancas, 2015), permitiendo el otorgamiento ilimitado de las preceptivas autorizaciones previas para la construcción de hoteles de cinco estrellas o superior, que "cumplan con las máximas exigencias de eficiencia energética y ahorro de agua" (artículo 4.4 de la Ley 2/2013). Sin embargo, no sucede lo mismo con la construcción de nuevos alojamientos turísticos de cuatro estrellas, en cuanto queda condicionada a la obligación de acometer la renovación edificatoria de la oferta alojativa existente; ésta será la cuestión central del conflicto, esto es, la exigencia de autorización 
turística previa. En la medida en que verifica y determina la compatibilidad del destino turístico de un establecimiento de alojamiento turístico con la ordenación territorial turística y la normativa sectorial aplicable, la transcendencia de este tipo de autorización administrativa de naturaleza reglada radica en que constituye uno de los deberes fundamentales que se impone a los empresarios turísticos para el ejercicio de sus actividades (artículos 13.2.b y 21 de la Ley 7/1995, de 6 de abril, de Ordenación del Turismo de Canarias, modificada por la Ley 7/1997, de 4 de julio, de Ordenación del Turismo de Canarias, actualmente derogada, por la Ley 5/1999, de 15 de marzo). $\mathrm{Su}$ obtención opera como un auténtico requisito de validez - y no sólo de eficaciade las licencias de cualquier tipo (de obras, de apertura, etc.), a concederse en suelo calificado como turístico, sancionándose con la nulidad de pleno derecho todas las que fueren concedidas sin disponer previamente de la misma (artículo 61 de la Ley 7/1995). Su ausencia determina la nulidad de la licencia de obras. Ello explica el calificativo de "previa", en cuanto su otorgamiento resulta un requisito anterior e ineludible para su obtención.

Esta estrategia de vincular el otorgamiento de nuevas autorizaciones turísticas previas a la renovación de los establecimientos existentes supone un mecanismo de fomento del proceso. Implica la equiparación entre plazas renovadas y nuevas susceptibles de ser autorizadas, en la medida en que la asignación y el techo de plazas alojativas materializables están relacionados directamente con el número de operaciones de renovación edificatoria acometidas. Con ello se pretende evitar el rejuvenecimiento de las áreas turísticas únicamente a través de la incorporación de nuevas plazas turísticas. Por tanto, supone recuperar las situaciones de old-fashioned (pasado o fuera de moda) de los establecimientos de alojamiento turístico y, por tanto, las zonas pioneras de las áreas turísticas, desde la premisa de que éstas se ubican, en su mayoría, en los ámbitos de litoral más privilegiados desde el punto de vista del potencial turístico.

Aunque la categoría mínima inicial no está limitada, la resultante de esta obligación debía ser, al menos de cuatro y tres estrellas en establecimientos hoteleros y apartamentos, respectivamente, $y$, en ningún caso, inferior a la sustituida (artículo 10 de la Ley 2/2013). Esta limitación exclusiva a la "gama alta" de los establecimientos alojativos pretende orientar, vía modalidad y categoría, el modelo alojativo turístico de Canarias hacia la opción de mayor impacto sobre los principales indicadores del negocio turístico y de la rentabilidad empresarial (número de pernoctaciones, estancia media, índices de ocupación, tarifa media diaria, ingreso medio diario por habitación disponible y ocupada, etc.). A su vez, aunque resulta recurrente el error conceptual de asociar más calidad a más estrellas (Francisco, 2003), se opta por una estrategia de upgrading, al plantearse como un proceso ascendente en la cadena de valor a través del alejamiento de las actividades con bajas barreras de entrada, en las que la competitividad debe residir esencialmente en los costos de producción. Del mismo modo, supone una aproximación al paradigma cualitativo, a través del reposicionamiento hacia aquellas actividades donde lo intangible e inmaterial representa un factor de competitividad esencial. 
Si bien cualquier empresario/propietario puede optar por la renovación de su establecimiento turístico siguiendo los trámites administrativos convencionales, esta estrategia posibilita su inclusión en los Planes de Modernización Mejora e Incremento de la Competitividad, con las consiguientes ventajas y que han sido sistematizadas por Simancas y Ledesma (2016), y, sobre todo, acogerse al conjunto de incentivos previstos en la Ley 6/2009 y ampliado en la 2/2013. Nos referimos, en concreto, a la posibilidad de obtener lo que hemos denominado como "plazas premios" (Santos et al., 2013; Simancas, 2015), derivadas de la sustitución de un alojamiento turístico o de su remodelación con incremento de categoría, de hasta un $50 \%$ en el caso de los hoteles de al menos cuatro estrellas y de un $25 \%$ en el de los apartamentos de tres llaves en relación con la capacidad alojativa original; estos porcentajes de plazas adicionales pueden incrementarse en un $25 \%$ más por cada grado de categoría que se aumente a partir de las tres estrellas, sin que en ambos casos se supere el $100 \%$ de las plazas preexistentes. En este sentido, la ejecución de 1.296 plazas alojativas correspondientes a ocho proyectos de renovación de complejos de alojamiento turístico en San Bartolomé de Tirajana y Mogán entre 2015 y 2017 han creado una "bolsa" de 1.217 plazas premio. Este incentivo pretende que la inversión en operaciones de renovación alojativa resulte atractiva para los propietarios/gestores de los alojamientos turísticos obsoletos que no quieran —o puedan - materializar las plazas adicionales resultantes de su renovación en relación con dos cuestiones básicas:

a) Como fuente de financiación, en cuanto los propietarios pueden obtener la necesaria para abordar los costes de renovación a través de la venta o cesión de los derechos a un tercero. De esta manera, se crea un mercado de derechos en el ámbito territorial de cada isla, que dota de valor a los derechos adquiridos de nuevas plazas de alojamiento (Santos et al., 2013).

b) Como mecanismo de obtención de las preceptivas autorizaciones turísticas por parte de aquellos empresarios interesados en construir alojamientos de cuatro estrellas, que no pueden o quieren optar por la construcción de hoteles de cinco estrellas, y que no son titulares de un alojamiento que ha sido previamente objeto de renovación. Así, la compra de las citadas "plazas premio" posibilita la obtención de derechos materializables en plazas hoteleras, con lo que pueden entrar en el mercado turístico. Esto convierte a las actuaciones de renovación de las plazas turísticas obsoletas inferiores a las cuatro estrellas en una forma estratégica de obtención de tales derechos de nuevas autorizaciones.

A pesar de estas potencialidades, esta decisión pública de supeditar la construcción de nuevos hoteles de cuatro estrellas a la renovación previa de los alojamientos turísticos ha sido controvertida, siendo ampliamente cuestionada por empresarios de Gran Canaria. Se trata de los actores "damnificados" y aparentemente más débiles por la aplicación de esta estrategia pública de renovación. Este rechazo se debe a su dificultad para cumplir con tal condicionamiento $\mathrm{y}$, por ende, para acceder a cualquiera de las dos ventajas señaladas. Ello se debe a una serie de cuestiones básicas; éstas constituyen los elementos materiales esenciales del conflicto. 
En primer lugar, el elevado coste de la estrategia proyectada, en cuanto implica invertir en un establecimiento alojativo obsoleto o deteriorado antes de afrontar la construcción de uno nuevo. A ello se añade la necesidad preceptiva de adecuarse a la inversión mínima por plaza de alojamiento turístico, fijada inicialmente en el Decreto $138 / 2010$ y que la Ley $2 / 2013$ incrementó hasta un $50 \%$. Se trata de una inversión que condiciona el régimen de garantía de la ejecución del proyecto de renovación, entre otras cuestiones, porque implica disponer del importe total de la misma, cuando no todos requieren de la misma cuantía, a la vez que un gran número de empresarios prefieren acometer reformas parciales de su establecimiento, con el fin de evitar su cierre total temporal.

En segundo lugar, aunque las especiales características del mercado inmobiliario en las áreas turísticas consolidadas hacen difícil que el coste de adquisición de un alojamiento turístico, sobre todo, los de reciente construcción, sea inferior al de su renovación, la primera opción puede resultar más atractiva que la segunda. A la vez, es evidente que el coste financiero-fiscal de invertir en la construcción de nuevas plazas es inferior a la inversión en inmuebles antiguos.

En tercer lugar, los empresarios prefieren construir un hotel de cuatro estrellas en lugar de uno de cinco. Entre los factores determinantes de esta preferencia, podemos destacar los siguientes:

- El diferente coste económico de la construcción de un hotel de cuatro estrellas respecto al de cinco. Según el Informe "Mercado Hotelero 2014" (Tinsa, 2015), construir un hotel de 5 estrellas en España supone una inversión media de 262.000 euros por habitación, el doble que uno de 4 estrellas, con 135.000 euros, y el triple que un alojamiento de 3 estrellas, cuyo promedio es de 89.000 euros.

- Las complicaciones inherentes a la comercialización y gestión (explotación) del segmento de los establecimientos de cinco estrellas.

- La dificultad de cumplir con los estándares establecidos en el Decreto 142/2010, de 4 de octubre, por el que se aprueba el Reglamento de la Actividad Turística de Alojamiento y modifica el Decreto 10/2001, de 22 de enero. Ello se explica por el tamaño mínimo de las parcelas resultantes de su aplicación, en cuanto la superficie de la unidad de alojamiento de un hotel de cinco estrellas se incrementa $3 \mathrm{~m}^{2}$ por cada 2 plazas (28) respecto a la de cuatro (25); lo mismo sucede respecto a las zonas generales, para las que es un $0,25 \mathrm{~m}^{2}$ por plaza más grande en los hoteles de cinco estrellas (2) que para los de cuatro $(1,75)$.

- El intento de evitar el posible conflicto con los operadores que ya controlan este segmento en Gran Canaria, que, a su vez, son los propietarios del capital, el suelo y los alojamientos, llegando, en algunos casos, a dominar el poder político.

En cuarto lugar, la ausencia de suelos urbanizables de uso turístico y urbano no consolidado ya clasificados en los que ubicar los nuevos hoteles de cuatro estrellas derivados de la obtención de las "plazas premios". Según el informe de Gesplan (2012), de los $54.376 .355 \mathrm{~m}^{2}$ de suelo calificado como turístico en 2011, Gran Canaria era la isla con un menor porcentaje (el 17,1\%), seguida de Fuerteventura $(22,5 \%)$, Tenerife $(23,2 \%)$ y Lanzarote $37,2 \%)$. La situación se complica por las 
determinaciones de la Directriz 7.2.a de Ordenación del Turismo y la Ley 2/2013, que mantuvieron la restricción de clasificación de nuevos suelos urbanizables con destino de uso turístico.

A todo lo anterior se añadieron las escasas posibilidades reales de incorporación de nuevas plazas de cuatro estrellas sin vincularse a los procesos de renovación edificatoria. Según los datos aportados en una respuesta parlamentaria 8L/PE-5424del 19 de diciembre de 2013 (Boletín Oficial del Parlamento de Canarias, de 16 de enero de 2014, $\mathrm{n}^{\circ}$ 6), Gran Canaria acapara el 39,1\% de las 2.568 plazas hoteleras de cuatro estrellas con autorización previa concedida sin ejecutar o que no se han abierto con posterioridad a la entrada en vigor de la Ley 19/2003 en las islas consolidadas turísticamente, seguida de Lanzarote (33\%), Tenerife $(27 \%)$ y Fuerteventura $(0,9 \%)$. De esta manera, sólo ocho hoteles de cuatro estrellas se podían construir en estas islas a razón de tres en Gran Canaria, dos en Tenerife y Lanzarote y uno en Fuerteventura, quedando limitada la posibilidad de autorización de nuevas plazas únicamente a las derivadas de los mismos.

En quinto lugar, dada la preponderancia en una proporción de $2 / 1$ de la oferta de alojamiento extrahotelero (apartamentos y bungalows) en Gran Canaria, los empresarios de esta isla consideraron que la estrategia de renovación suponía un agravio competitivo para la misma respecto a otras consolidadas turísticamente del Archipiélago, y, sobre todo, Tenerife, que había apostado por un modelo hotelero de cuatro y cinco estrellas, que, a la larga, se ha demostrado acorde con la tendencia mundial: mientras esta última isla concentraba el $40,1 \%$ de las plazas turísticas igual o superior a 4 estrellas del Archipiélago en 2012, Gran Canaria sólo el 21,9\%; a su vez, Tenerife acaparaba el $72,7 \%$ de la oferta hotelera de 4 y 5 estrellas, frente al $55,1 \%$ de Gran Canaria. La elección de este modelo alojativo en Gran Canaria se debió a que era una modalidad susceptible de acoger fórmulas de explotación con un bajo nivel cuantitativo de profesionalización del sector, la heterogeneidad y dispersión de los capitales que intervienen en el "negocio" turístico, así como los modos de producción del espacio turístico y, en concreto, la intensa vinculación entre lo turístico y lo inmobiliario, o mejor dicho, el predominio de la actividad especulativa-inmobiliaria sobre la turística y de acumulación de capitales. Asimismo, las extraordinarias expectativas de rendimiento atrajeron a agentes productores -en detrimento de los que explotan el negocio turístico con voluntad de permanencia-, los cuales no promocionaron los inmuebles hasta que no eran financiados mediante el abono del precio de repercusión de referencia. De igual manera, la construcción y puesta en explotación de este tipo de oferta extrahotelera requería un capital inicial menor que para la hotelera, siendo, además, un intento de obtener una rentabilidad inmediata con poca inversión. Asimismo, la compra de una unidad extrahotelera se convirtió en una forma de ahorro local familiar o de inversión de profesionales, que, ante la expectativa de autofinanciación y de convertirse en una fuente complementaria de recursos, adquirían uno o varios apartamentos o bungalows mediante el sistema de venta anticipada (sobre planos). Del mismo modo, a diferencia del negocio hotelero, que requiere la permanencia continuada en el mercado y la garantía de suficientes tasas de ocupación, los establecimientos extrahoteleros presentan menos costes, más 
diversidad de fórmulas de explotación y unos mayores márgenes de maniobrabilidad. Por último, la "congelación" de una importante cantidad de suelo destinado al uso hotelero casi en su totalidad, como consecuencia de la reclasificación como suelo rústico de protección de los sectores de Tauritos II (S.A.U. Polígono 32, N.S. Mogán), Montaña Alta de Tauro (S.A.U. Polígono 14, N.S. Mogán), Cortadores (S.A.U. Polígono 26, N.S. Mogán), Veneguera (S.A.U. Polígono 33, N.S. Mogán) y las zonas correspondientes de Costa Tauritos (Área con planeamiento turístico vigente, N.S. Mogán), en virtud del Decreto 7/1995, de 27 de enero, por el que se aprueba definitivamente el Plan Insular de Ordenación de la isla de Gran Canaria, constituyó otro factor determinante del predominio de este tipo de oferta de alojamiento extrahotelero en esta Isla.

Dicha consideración de agravio se debió, entre otras circunstancias, a que la renovación de la oferta alojativa extrahotelera resulta extremadamente compleja, dado que las situaciones de obsolescencia (física, funcional, de modelo de negocio, de modelo organizativo, formas de segmentación, canales de venta, etc.) producen un deterioro continuo de los márgenes empresariales y de la rentabilidad privada y social de este tipo de complejos turísticos. La consecuencia inmediata era una pérdida de capacidad de competitividad, cuota de mercado y rentabilidad empresarial, hasta el punto de lograrse unos niveles que, en la mayoría de los casos, sólo cubren los costes de explotación, llegando a ser inferiores, incluso, a la cuota de la comunidad de propietario. Ello se agrava por el hecho de que sus propietarios también suelen ser reticentes a sufragar derramas, con arreglo a la cuota de participación y, por tanto, la aplicación de la legislación de propiedad horizontal (Simancas, 2016). Asimismo, las particulares condiciones de atomización y dispersión de la propiedad de las unidades alojativas favorecen la diversidad de usos de las mismas por parte de sus propietarios $\mathrm{y}$, por tanto, diferentes posiciones ante la decisión de acometer su renovación. Todo lo anterior determina que los propietarios no inviertan en operaciones de renovación, ni siquiera las obligatorias de conservación.

La última razón de oposición se relaciona con el hecho de que, considerando que las relaciones de poder son asimétricas, el grupo de empresarios turísticos de Gran Canaria consideró que la decisión de vincular la construcción de nuevos establecimientos de alojamiento turístico de cuatro estrellas con la renovación edificatoria de los existentes estaba impuesta no sólo por algunos operadores ya instalados en el mercado turístico insular, con el fin de evitar el crecimiento de la competencia interna. Lo mismo se planteó respecto a la Asociación Hotelera y Extrahotelera de Tenerife, La Palma, La Gomera y El Hierro (Ashotel), al considerase que pretendía impedir el crecimiento de plazas turísticas en Gran Canaria, con el fin de evitar el equilibrio interinsular de la oferta de alojamiento turístico. Así, el citado grupo consideró que estos definitive stakeholders habían procedido a la "captura del regulador", aprovechando su "poder para" la toma de decisiones y su "poder sobre" la Administración Pública con competencia legislativa (Lukes, 1985), imponiendo sus intereses, creando esquemas limitados de participación y controlando la agenda y el discurso político. 


\subsection{El nudo del conflicto: la judicialización de la estrategia}

Considerando que en cualquier conflicto funciona el principio de "causalidad múltiple", es decir, no existe una sola razón de divergencia, las anteriores cuestiones explican el surgimiento del conflicto. Tomando como referencia las tres formas de posicionamiento de los actores ante un conflicto señaladas por Hirschman (1970), los empresarios "damnificados" u "olvidados" de la estructura de gobernanza hicieron "uso de la palabra o voice". La oposición fue contra el Gobierno de Canarias, con la voluntad de modificar la decisión de condicionar la construcción de nuevos establecimientos de alojamiento turístico de cuatro estrellas a la renovación edificatoria de los existentes. Entendieron que aquél era el actor responsable de la disimetría del conflicto, al haber ejercido su poder coercitivo y homogeneizador a través del habitual modelo burocrático, de organización piramidal y control jerárquico para fijar una norma que no les favorecía. De esta manera, se alejó de lo que se entiende por buen gobierno del territorio, al no generar un consenso y un escenario de transparencia, con soluciones win-win ("todos ganan"), aceptables y satisfactorias para todas los agentes.

Estos empresarios "perjudicados" buscaron alianzas estratégicas con grupos de presión de la esfera empresarial, entre otros, la Federación de Empresarios de Hostelería y Turismo, el Círculo de Empresarios de Gran Canaria o el Centro Atlántico de Pensamiento Estratégico. Asimismo, recibieron el apoyo de la oposición política partidista, en concreto, Presidencia del Cabildo Insular ${ }^{3}$, gobernado por el Partido Popular - y, por tanto, distinto al del Gobierno de Canarias-y los diputados regionales del Partido Popular y Nueva Canaria. Como se puede apreciar, el conflicto es el responsable de este proceso de colaboración de actores que tuvieran la necesidad de cooperar. Así, se configuró una estructura integrada por una variedad de actores que comparten intereses comunes en referencia a la estrategia pública de renovación de los alojamientos turísticos y que dispone de diversos recursos y capacidad de influencia.

Los empresarios damnificados van a utilizar esta red como un instrumento para ejercer su poder e incitar un nuevo proceso de negociación a través de actuaciones de presión política. El efecto inmediato fue $\boldsymbol{e l}$ anuncio en prensa el 17 de febrero de 2013 por el entonces ministro grancanario de Industria, Energía y Turismo de presentación de un Recurso de Inconstitucionalidad contra los apartados a) y c) del artículo 4.2 de la Ley 2/2013 por parte del Gobierno de España. La iniciativa fue apoyada por el Ayuntamiento de Mogán y la Federación de Empresarios de Hostelería y Turismo de

\footnotetext{
${ }^{3}$ Los Cabildos Insulares constituyen, sin ninguna duda, la mayor singularidad del régimen político-administrativo de Canarias, tanto por su arraigo histórico, como por la gran carga competencial que han ido asumiendo. Se trata de órganos de gobierno de las "islas", creadas en 1912, las cuales, junto a los municipios y las provincias, tienen el carácter de entidades locales territoriales básicas o de existencia obligatoria.
} 
Las Palmas. Consideramos que sobre esta decisión influyó decisivamente el enfrentamiento político y mediático entre dicho ministro (Partido Popular) y el Presidente del Gobierno de Canarias (Coalición Canaria), entonces apoyado por los grupos parlamentarios Nacionalistas Canarios y Socialistas Canarios; por tanto, se trató de una causa esencialmente política.

Dicho anuncio dio lugar a la creación el 25 de julio de 2013 de una Comisión Bilateral de Cooperación Administración General del Estado-Comunidad Autónoma de Canarias entre el vicepresidente del Gobierno de Canarias y el Ministro de Hacienda y Administraciones Públicas. El Acuerdo para iniciar las negociaciones para resolverla se publicó en virtud de la Resolución del 2 de septiembre de la Secretaría General de Coordinación Autonómica y Local.

Tras agotarse los intentos de acuerdo en el seno de la esa Comisión Bilateral, el Consejo de Ministros celebrado el 21 de febrero de 2014, solicitó al Presidente del Gobierno del Reino de España que interpusiera el citado Recurso, lo que hizo ese mismo día. Su redacción tuvo como referencia los siguientes documentos, cuya formulación supuso la incorporación de nuevos actores públicos al conflicto:

a) Un Informe del Ministerio de Economía y Competitividad, de 19 de junio de 2013. Señala que la regulación contenida en los apartados a) y e) del artículo 4.2 de la Ley 2/2013 de Canarias supone "una barrera casi total a la entrada de nuevos operadores y, por tanto, un cierre de mercado". Asimismo, recuerda que la exigencia de requisitos económicos para el acceso a una actividad de servicios está prohibida por el artículo 10 de la Ley 17/2009, de 23 de noviembre, sobre el libre acceso a las actividades de servicios y su ejercicio, que sustituye la autorización previa por la declaración responsable y la comunicación previa. Como es sabido, esta norma derivó del actual proceso de liberalización propugnado por la política de fomento de la competencia de la Unión Europea, en concreto, la transposición parcial a nuestro ordenamiento nacional de la Directiva 2006/123/CE del Parlamento Europeo y del Consejo, de 12 de diciembre de 2006, relativa a Servicios del Mercado Interior(DOUE L 376, de 27-12-06).

b) Un Informe de la Subdirección General de Cooperación y Competitividad Turística del Ministerio de Industria, Energía y Turismo, de 23 de julio de 2013, en el que igualmente se advierte que la norma autonómica da lugar en la práctica a un cierre de mercado, en la medida en que sólo permite la construcción de hoteles y apartamentos de determinada categoría.

c) Un Informe de la Dirección General de Coordinación de Competencias con las Comunidades Autónomas y las Entidades Locales del Ministerio de Hacienda y Administraciones Públicas, de 16 de enero de 2014. Analiza los motivos en que se sustenta la impugnación pretendida en términos coincidentes con el informe anterior.

d) El Dictamen 71/2014, de 6 de febrero de 2014, de la Comisión Permanente del Consejo de Estado, sobre la interposición del citado recurso. Éste concluye que el régimen de otorgamiento de autorizaciones previsto en las letras a) y e) del artículo 4.2 de la Ley $2 / 2013$ puede resultar contrario a la regulación contenida en la Ley básica 17/2009, de 23 de noviembre. 
El Recurso de Inconstitucionalidad se fundamentó en la premisa de que la determinación de otorgar autorizaciones previas sólo para establecimientos hoteleros con categoría de cinco estrellas o superior (apartado a) del artículo 4.2 de la Ley $2 / 2013$ ) y para aquellos que solicitasen modificarla, sin incremento del número de plazas ya autorizadas (apartado c) del artículo 4.2, vulneraba el título competencial estatal recogido en el artículo 149.1.133 de la Constitución Española. De esta manera, el recurso no se presentó contra la Ley 2/2009 que lo prohíbe, sino contra sus excepciones, que, en último término, son las que permitían la construcción de nuevos alojamientos turísticos.

A su vez, el Recurso abordó la cuestión central del conflicto, esto es, la exigencia de autorización turística previa. La Ley 6/2009 pudo mantenerla, debido a que se promulgó unos meses antes de la promulgación de la Ley 17/2009. Por su parte, la Ley 2/2013 modificó el artículo 24.2 de la Ley 7/1995 operada por la 14/2009, argumentando su necesidad en la dimensión ambiental de la sostenibilidad, con el fin de que la exigencia de las autorizaciones turísticas previas resultase proporcionada con las determinaciones y objetivos de la Ley 17/2009. Sin embargo, ahora se consideró que la exigencia de autorización turística previa era contraria al principio de libertad de establecimiento de los prestadores de servicios turísticos pretendido con la Ley 17/2009, pues, aunque, en términos generales, se ampara en una razón imperiosa de interés general, se conecta en los supuestos previstos en los apartados mencionados con criterios o requisitos de naturaleza económica, en contra de lo que establece la norma estatal, limitando, por tanto, el acceso y ejercicio de actividades turísticas por criterios económicos.

El Recurso fue admitido a trámite (número 1133-2014) por el Pleno del Tribunal Constitucional con fecha de 10 de marzo de 2014. A solicitud de la Abogacía del Estado, el Tribunal acordó la suspensión correlativa de la vigencia y aplicación de los preceptos impugnados desde la fecha de interposición del recurso ( 25 de febrero de 2014) y la publicación en Providencia (Boletín Oficial del Estado, ${ }^{\circ}$ 63, de 14 de marzo de 2014). Ello supuso la imposibilidad automática e inapelable de otorgar autorizaciones previas para nuevos alojamientos turísticos hoteleros y extrahoteleros en Lanzarote, Fuerteventura, Gran Canaria y Tenerife que no provinieran de la renovación o alguno de los otros supuestos, tasados y no afectados por la suspensión, contenidos en el artículo 4.2. De esta manera, la construcción de hoteles de cinco estrellas y superior quedó prohibida. El impacto directo de esta medida fue la paralización de la concesión de la licencia para la construcción de tres y dos hoteles de cinco estrellas en Tenerife (Guía de Isora y Adeje) y Gran Canaria (Mogán y San Bartolomé de Tirajana), respectivamente, lo que suponía unas 2.450 plazas. Esto supuso un ejemplo de judicialización de una acción pública de gobierno del turismo, a la vez que recurrir a un procedimiento que quedó por encima del Gobierno de Canarias.

La respuesta inmediata del Gobierno de Canarias a este Recurso de inconstitucionalidad fue la promulgación del Decreto 17/2014, de 14 de marzo, sobre los efectos en el otorgamiento de licencias urbanísticas, de la suspensión de la 
vigencia y aplicación de los apartados a) y c) del artículo 4.2 de la Ley $2 / 2013$, de 29 de mayo, de renovación y modernización turística de Canarias, publicado el sábado 15 de marzo de 2014, en un número extraordinario del Boletín Oficial de Canarias. Se trató de una norma que, a propuesta conjunta del Presidente y del Consejero de Obras Públicas, Transportes y Política Territorial, fue decidida en una sesión extraordinaria del Consejo de Gobierno celebrada el día anterior a su publicación. Constituyó una solución paliativa y de anticipación ante la incertidumbre empresarial y la inseguridad jurídica generada por el Recurso. El resultado fue la suspensión del otorgamiento de las licencias urbanísticas para edificios destinados a alojamiento turístico relacionadas con ambos supuestos en las cuatro islas consolidadas turísticamente del Archipiélago. Esto modificó sustancialmente el mecanismo de renovación alojativa contemplado hasta el momento: mientras que en las Leyes 19/2003, 6/2009 y 2/2013 no suponía una obligación, la Ley 9/2015 lo establece no sólo como un trámite forzoso para todo empresario que quiera construir un hotel de cuatro estrellas, sino también lo convierte en la única opción para obtener las autorizaciones turísticas previas previstas en la Ley 7/1995. De esta manera, la situación anterior se ha invertido, en la medida en que la renovación edificatoria se convierte en la regla general y obligatoria para poder construir ese tipo de establecimiento, constituyendo la única posibilidad para incorporación nuevas plazas alojativas.

En conformidad con lo establecido al respecto en la Ley Orgánica 2/1979, de 3 de octubre, el Tribunal Constitucional debía decidir antes de cinco meses, si prolongaba esa suspensión temporal cautelar o, en su caso, la levantaba, sin que ello supusiera pronunciarse sobre el fondo del asunto, al tratarse de una cuestión relegada a la sentencia definitiva, susceptible de demorarse cuatro o cinco años. A través del Auto del 24 de junio de 2014, notificado a las partes el 2 de julio - y, por tanto, antes de acabar el citado plazo preceptivo-, dicho Tribunal acordó levantar la suspensión cautelar de los dos apartados recurridos. Esta decisión se sustentó en el hecho de que el Gobierno de España no fundamentó los perjuicios ocasionados por ambas determinaciones objeto de recurso, por lo que se mantuvo la presunción de constitucionalidad de la norma. Asimismo, estimó que el argumento del recurso estatal de que la prohibición de impedir nuevos establecimientos hoteleros y extrahoteleros de una categoría a las cinco estrellas "causa unos graves e irreparables perjuicios económicos al interés general" no es consecuencia de tales determinaciones, ya que no prohíben la autorización de nuevos hoteles de cinco estrellas o de categoría superior, sino justo lo contrario. El Auto reconoce implícitamente que dicho Recurso estaba mal enfocado, a la vez que estima que lo único que la suspensión cautelar solicitada había logrado era el bloqueo durante un tiempo indeterminado de la incorporación de nuevas plazas turísticas, debido a la consiguiente incertidumbre jurídica. El efecto inmediato de este levantamiento de la suspensión fue la concesión el día 17 de julio por parte del Ayuntamiento de Mogán de la licencia para la construcción de un hotel de cinco estrellas en las parcelas señaladas como $26^{\mathrm{a}}$, 26b y 27 del Plan Parcial Lomo Quiebre.

Finalmente, la Sentencia 209/2015, de 8 de octubre de 2015, el Tribunal Constitucional falló "estimar el presente recurso de inconstitucionalidad y, en 
consecuencia, declarar que el apartado a) y el último inciso del apartado e\}, en la parte que se refiere a los apartamentos de cinco estrellas o superior, del artículo 4.2 de la Ley 2/2013, de 29 de mayo, de renovación y modernización turística de Canarias, en su redacción inicial, son contrarios al orden constitucional de distribución de competencias y, por tanto, inconstitucionales y nulos".

\subsection{El desenlace del conflicto: la flexibilización de la estrategia}

La moción del grupo político Nueva Canarias-Nueva Gran Canaria, aprobada el 21 de octubre de 2013 por la mayoría absoluta del Pleno Insular (21 de los 29 consejeros $^{4}$ ), dio lugar a una Proposición de Ley del Cabildo Insular de Gran Canaria que planteó la modificación de la Ley $2 / 2013$. Ésta propuso dos cuestiones básicas: por un lado, la recuperación de las competencias de los Cabildos en esta materia, con la consiguiente insularización del modelo de ordenación territorial del turismo, lo cual resultaba lógico tras la aprobación del Plan Territorial Especial de Ordenación Turística Insular (febrero de 2014); y por otro, que Gran Canaria quedara exenta por un periodo evaluable de tres años de la aplicación de la estrategia de vincular la construcción de hoteles de cuatro estrellas a la renovación previa de otros establecimientos, pudiendo otorgarse autorizaciones administrativas previas para aquellos hoteleros y extrahoteleros, con categoría de cuatro estrellas o superior, siempre y cuando el número de plazas de cuatro estrellas no superase el $40 \%$ del total de plazas alojativas turísticas registradas legalmente en la isla, fijando un límite anual de un $4 \%$. Ésto posibilitaría la entrada en el mercado de hasta 5.600 plazas nuevas anuales con categoría de cuatro estrellas, lo que posibilitaba que la oferta alojativa insular pasara del 18 al 40\%. Tras su admisión por el Consejo de Gobierno de Canarias el 28 de noviembre de 2013, éste la comunicó al Parlamento (8L/PPLC0004) para su toma en consideración.

Esta propuesta pone de manifiesto una serie de cuestiones básicas del conflicto. En primer lugar, la necesidad de adecuar las políticas públicas a la diferencias y las diversidades territoriales; no obstante, sobre esta pretensión se aprecia cierto síndrome Nimby (Not In My Back Yard, "no en mi jardín, no en mi patio"), o lo que algunos han rebautizado en español como Span (Sí, pero aqui no) (Gravano, 2011), dándose, por consiguiente, un proceso de oposición a una decisión por un comportamiento partidista, sin preocupaciones por el interés general de las áreas turísticas. En segundo lugar, el reconocimiento de la situación de "atasco" que supone la habitual falta de coordinación y de cooperación entre los distintos niveles administrativos, derivada de la tendencia a las competencias exclusivas en lugar de

\footnotetext{
${ }^{4}$ Los votos a favor fueron de los diecinueve consejeros de los grupos de gobierno del Partido Popular (14) y de Nueva Canarias-Nueva Gran Canaria (5). Por su parte, el Grupo Coalición Canaria se abstuvo y los siete consejeros del Grupo Partido Socialista Canario-PSOE votaron en contra.
} 
compartidas y concurrentes. En tercer lugar, el constante debate acerca de la escala geográfica más adecuada para la toma de decisiones (regional Vs insular); aunque ello denota un cierto interés insularista de aplicación del principio de subsidiaridad a la planificación territorial del turismo, con el fin de que "las decisiones se tomen donde suceden los hechos" y no en niveles competenciales superiores, en la práctica, se intuye lo que localmente se conoce como "pleito insular", y, por tanto, el más puro insularismo, entendido como una ideología 5 .

Esta iniciativa legislativa fue rechazada en la sesión plenaria del Parlamento de Canarias, celebrada el 12 de marzo de 2014, con los votos de los Grupos Parlamentarios Socialista Canario y Nacionalista Canario. No obstante, el Presidente del Gobierno planteó en mayo de 2014 la posibilidad de revisar la Ley 2/2013.

Los grupos empresariales $y$ políticos de Gran Canaria continuaron su presión, planteando tres alternativas: a) eliminar el condicionamiento de la construcción de nuevos hoteles de cuatro estrellas; su vinculación al cumplimiento de criterios de sostenibilidad (por ejemplo, la utilización de energías renovables), la generación de empleo, la creación ex novo de productos alojativos singulares (competencia cualificada); o c) su limitación únicamente a los suelos ya clasificados como urbanizables de uso turístico y urbanos no consolidados. A ello se añadió la intensificación a finales del año 2014 del enfrentamiento mediático entre los actores turísticos, públicos y privados, de Gran Canaria y Tenerife, sobre todo, con la patronal Ashotel.

De acuerdo con lo planteado en sede parlamentaria por el Presidente del Gobierno sobre la revisión de la Ley 2/2013, el Consejo de Gobierno de Canarias aprobó el 15 de enero de 2015 un Anteproyecto de modificación de la misma. Como ley de artículo único, éste se tramitó por el procedimiento de urgencia, en cuanto quedaban sólo cuatro meses para la celebración de las elecciones autonómicas, insulares y municipales.

Tramitada prácticamente al unísono que la Ley estatal 8/2013, de 26 de junio, de rehabilitación, regeneración y renovación urbanas, la modificación de la Ley 2/2013 se justificó formalmente por la necesidad de adaptarse a la misma, con el fin de corregir ciertas contradicciones y disfunciones. Del mismo modo, como se señala en el preámbulo del Anteproyecto, se pretendía "incentivar el proceso [de renovación] ya iniciado, eliminando o corrigiendo las rigideces innecesarias que se han detectado y que, de subsanarse, pueden conseguirse un mayor éxito y mayor eficacia para lograr los objetivos de la Ley 2/2013". Sin embargo, creemos que, en realidad, esta modificación fue consecuencia directa de la presión de los citados "lobbies"

\footnotetext{
${ }^{5}$ El pleito insular es la expresión coloquial que hace referencia al conflicto competencial y administrativo, principalmente entre las dos islas centrales (Gran Canaria y Tenerife), por la capitalidad del Archipiélago y, por ende, por la hegemonía económica, política e institucional, que se inició, sobre todo, a partir de la denominada Ley de Cabildos de 11 de junio de 1912, la cual dio lugar a una nueva organización administrativa regional, así como de la división provincial en 1927.
} 
empresariales, en un intento de lograr un cierto consenso a escala regional. A su vez, pretendió solventar algunas debilidades de la estrategia de renovación puestas de manifiesto en el Informe de Evaluación de la Ley 2/2013 de Renovación y Modernización Turística (Gobierno de Canarias, octubre de 2014), la necesidad de clarificar determinados preceptos o corregir omisiones de la norma, así como las "dificultades" generadas en la aplicación del modelo vigente. Del mismo modo, aunque no se explicita en la iniciativa legislativa tramitada, la modificación de los artículos 4.2.a) y c) de la Ley $2 / 2013$ pretendió satisfacer las alegaciones del Estado con ocasión de la presentación del citado Recurso de Inconstitucionalidad, desactivándolo $\mathrm{y}$, por tanto, resolviendo el proceso pendiente ante la jurisdicción constitucional; a este respecto, sorprende que solo cinco días después de que el Consejo de Gobierno enviara el texto del Borrador de reforma al Consejo Consultivo de Canarias, tres grupos empresariales, Lopesan, Santana Cazorla y Del Castillo, manifestaron su pretensión de construir quince hoteles de cuatro estrellas, a razón de 4,5 y 6 establecimientos, respectivamente, con la consiguiente incorporación al mercado de unas 22.000 plazas turísticas (Periódico La Provincia de 19 de enero de 2015).

Tras la emisión del preceptivo Dictamen del Consejo Consultivo, el Consejo de Gobierno aprobó el 12 de febrero el Proyecto de Ley 8L/PL-0028, siendo remitido al Parlamento de Canarias para su aprobación en lectura única, con el fin de garantizar su entrada en vigor antes de que terminase la VII Legislatura. Así, se promulgó la Ley 9/2015, de 27 de abril. Ésta no se ha limitado a pequeños cambios de la Ley 2/2013, sino que, apenas veinte meses después de su aprobación, ha modificado numerosos apartados de al menos cinco artículos y dos disposiciones transitorias, así como la introducción de seis disposiciones nuevas (adicionales, transitorias y derogatorias).

Sin embargo, este condicionamiento constituyó un simple formalismo para ceder a dicha presión política y empresarial. Ello se debe a que, como pone de manifiesto los Dictámenes 44/2015 del Consejo Consultivo de Canarias y 1/2015 del Consejo Económico y Social de Canarias, las exigencias relativas a los estándares de calidad edificatoria y de suficiencia energética ya están recogidas en normas sectoriales aplicables a las edificaciones turísticas, singularmente el Código Técnico de la Edificación (Real Decreto 314/2006, de 17 de marzo) y el Reglamento por el que se regula el procedimiento básico para la certificación energética de los edificios (Real Decreto 235/2013), o en el ámbito autonómico, por los Decretos 10/2001 y 142/2010, siendo de obligado cumplimiento.

Esta modificación no sólo constituye un intento de resolver el proceso pendiente ante la jurisdicción constitucional, sino también una reacción a la Sentencia favorable del Tribunal Superior de Justicia de Canarias de 3 de diciembre de 2004, que estimó el recurso de determinados preceptos del Decreto 142/2010, interpuesto por Ifa Hotel Continental, S.A. Entre otras cuestiones, plantea que la utilización del régimen excepcional por razones ambientales o de Ordenación del Territorio ya prevista en Ley 14/2009, que hizo que la excepción se transformase en regla, no es proporcionada, pues supone una duplicidad de licencias y controles administrativos, que no se justifica "por la razón imperiosa de interés general", a la vez que "constituye un 
fraude de Ley, por cuanto no existe una relación directa entre el criterio aplicadoautorización previa - y las razones imperiosas que se pretenden salvaguardar protección al medio ambiente y urbanismo - [...]". Esta decisión judicial retrotrajo la posibilidad de incorporar nuevas plazas turísticas al escenario anterior a la Ley 7/1995, al eliminar el requerimiento de la autorización previa.

Lo anterior explica la solución que ofrece la Ley 9/2015, pues, aunque mantiene la exigencia de autorización previa para la implantación de nuevos establecimientos de alojamiento turístico en Lanzarote, Fuerteventura, Gran Canaria y Tenerife, cambia los apartados a) y e) del artículo 4.2 de la Ley 2/2013, con la consiguiente modificación de los supuestos de otorgamiento de la preceptiva autorización. Así, esta nueva regulación establece dos caminos diferentes para conceder la autorización a un nuevo establecimiento de alojamiento turístico, diferenciando entre los proyectos de cuatro y cinco o más estrellas: mientras estos últimos puedan ejecutarse sin la previa autorización del Gobierno autonómico, solventándose así el mencionado reparo planteado por el Gobierno estatal, la autorización de los de una categoría inferior a cinco estrellas depende de la decisión completamente discrecional del Gobierno, sin que se establezcan criterios objetivos definidos para tomar esta decisión, a excepción del mero cumplimiento de la normativa de estándares turísticos y edificatorios de calidad y ecoeficiencia establecidos reglamentariamente por el Decreto 85/2015, de 14 de mayo. Este tratamiento diferenciado a favor de los establecimientos hoteleros y extrahoteleros de cinco estrellas o superiores se ha sustentado en la presunción de que éstos cumplen tales estándares.

Lo anterior determina que los establecimientos de alojamiento turístico ya no se diferencien en función de su calificación turística, a la vez que tampoco las restringe a una determinada categoría, y, por tanto, a criterios económicos. Por el contrario, la limita a criterios de naturaleza ambiental y de ordenación territorial, con lo que, en principio, no se vulnera la normativa básica estatal.

Lo anterior acaba definitivamente con las limitaciones parciales que aún estaban en vigor en relación con el crecimiento de nuevos establecimientos alojativos turísticos $-\mathrm{y}$, por tanto, con la moratoria turística-, quedando condicionadas a cuestiones de cumplimiento de criterios de ecoeficiencia energética y ahorro de agua. Asimismo, "fulmina" la eficacia de los incentivos, en cuanto la autorización de nuevas plazas turísticas, en concreto, la correspondiente a los hoteles de cuatro estrellas, ya no está condiciona a la renovación previa en otros establecimientos turísticos.

Por último, en coherencia a la citada Sentencia del Tribunal Constitucional 209/2015, de 8 de octubre de 2015, que declaró inconstitucionales y nulos los apartados señalados de la Ley $2 / 2013$, la redacción del nuevo apartado e) del artículo 4.2 continúa vulnerando la normativa básica estatal de conformidad con los fundamentos jurídicos y fallo de la misma. Por ello, el Gobierno de Canarias decidió el 26 de septiembre de 2016 aprobar el Proyecto de Ley por el que se deroga el apartado e) del artículo 4.2 de la Ley 2/2013. 


\section{Conclusiones}

Como en cualquier conflicto, el surgido por la estrategia de la política pública de vincular el otorgamiento de autorizaciones de construcción de nuevos hoteles de cuatro estrellas a la renovación de los establecimientos de alojamiento turístico obsoletos está implícito un problema de poder, su análisis realizado nos ha permitido examinar otros elementos claves, como la dialéctica de la oposición y la influencia de las relaciones de poder en el origen, dinámica y resolución del mismo. En este sentido, el espacio turístico, como espacio de poder, constituye una parte esencial en la noción del conflicto. Esto se debe, entre otras circunstancias, a que éste acontece en las áreas turísticas. Ello dota, a su vez, de una dimensión territorial a las relaciones de poder, dando cuenta de las formas de apropiación por parte de un grupo de actores.

Las causas que han generado el conflicto se relacionan, sobre todo, por las diferencias e intereses contrapuestos de los múltiples actores, públicos y privados, que se producen por esas relaciones de dominio y apropiación del espacio turístico por parte de un grupo de ellos. Así, en coherencia con el planteamiento de Krutwaysho y Bramwell (2010) acerca de que la implementación de las políticas debe ser examinada en términos de relaciones entre las disposiciones administrativas y los grupos de la sociedad civil implicadas, el análisis del conflicto no sólo nos ha permitido identificar la elevada pluralidad de actores estratégicos implicados (20), sino también las complejas interrelaciones, tanto de rivalidad, conflictividad, incompatibilidad o disfuncionalidad, como de complementariedad, simbiosis, e incluso, sinergia, que han existido entre lo público y privado, así como sus reacciones, así como las reacciones de estos últimos ante las decisiones de los primeros (figura 1).

La incapacidad gubernamental de dar respuesta a un conjunto de actores ("los perjudicados") ha generado el conflicto descrito, provocando su irrupción en el escenario público para exigir cambios en la normativa acordes con sus intereses. En este sentido, estimamos que la clave del conflicto ha sido la ausencia de espacios y cauces de participación necesarios y adecuados para alcanzar consensos, pactos y soluciones consensuadas. En gran medida, ello se debe, entre otras razones, a que ha fallado lo que Jamal y Getz (1995) denominan como la "colaboración entre partes interesadas" (stakeholder collaboration), entendida como proceso permanente y cooperativo de implicación, diálogo intenso y continuo y toma decisiones conjuntas entre las múltiples y diversas partes interesadas". Lo mismo ha pasado por la no inclusión de determinados actores $\mathrm{y}$, que, reaccionaron al verse perjudicados por la estrategia de renovación al no ajustarse a su modelo alojativo. De esta manera, como en cualquier conflicto, en éste existen partes, motivos y relaciones de poder.

Desde este punto de vista, el conflicto descrito se plantea como un caso especialmente interesante en donde se puede observar que la ausencia de gobernanza territorial deriva en problemas de gobernabilidad. De esta manera, las decisiones técnico-político-administrativas han resultado claves en la orientación y coordinación del conflicto, al formular, e incluso, "manipular", los marcos legales y los procedimientos administrativos que han regulado el proceso. Así, este conflicto ejemplifica la incompatibilidad que suele darse entre los objetivos individuales y el 
interés general utilizado por el poder público (técnicos y políticos). En cualquier caso, el conflicto puede considerase como beneficioso, al cuestionar la aplicación territorial de manera homogénea de la estrategia pública de renovación de los alojamientos turísticos, planteando la necesidad de adaptarla a la idiosincrasia de cada área turística.

El índice de impugnación y rechazo de la estrategia de vincular la autorización de nuevas plazas turísticas a la renovación de las existentes por parte de un grupo de actores, públicos y privados determinan que en su diseño e implementación no pueda hablarse de gobernabilidad, al obviarse sus expectativas. Así, aunque las distintas soluciones legislativas, planteadas desde el conflicto, han generado un escenario favorable de gobernabilidad, en la práctica, se alejan de lo que hubiera sido lo ideal. Ello se debe a que ha supuesto recurrir a la judicialización de las decisiones públicas, de modo que los problemas políticos son transferidos hacia la esfera judicial para su resolución, con los consiguientes efectos, pues como indican Domínguez y Muñoz (2013:10), "el hecho de que sean los jueces los que apliquen las suyas propias, cuando son las administraciones las que tienen la competencia natural sobre la elección del modelo de cada plan y su desarrollo, deriva en una perversión del sistema cuando la casuística es tan elevada".

El conflicto analizado ha tenido la capacidad de crear un nuevo esquema de reposicionamiento de los actores privados y públicos. Los perjudicados han desarrollado sus procedimientos internos de debate, a la vez que han creado instancias de negociación o de concertación más o menos institucionalizadas. Asimismo, los cambios en las relaciones entre los actores han posibilitado que estos últimos participen en la reformulación de política pública de renovación de los establecimientos de alojamiento turístico. Su resolución ha evitado que se alzasen barreras más altas entre las partes implicadas, a la vez que desinformación, desconfianza y parcialidad.

El proceso descrito supone un ejemplo de colaboración, en la línea que lo conciben Jamal y Getz (1995), esto es, como un proceso dinámico de resolución de problemas derivados de la planificación y de coordinación del desarrollo turístico local. Sin embargo, en la medida en que sigue una lógica cooperativa limitada en el tiempo, una vez que la solución del conflicto se ha producido, la colaboración se ha acabado. 
Figura 1. Sistema de relaciones del conflicto derivado del condicionamiento de la construcción de nuevos establecimientos de alojamiento turístico de cuatro estrellas a la renovación edificatoria de los existentes.

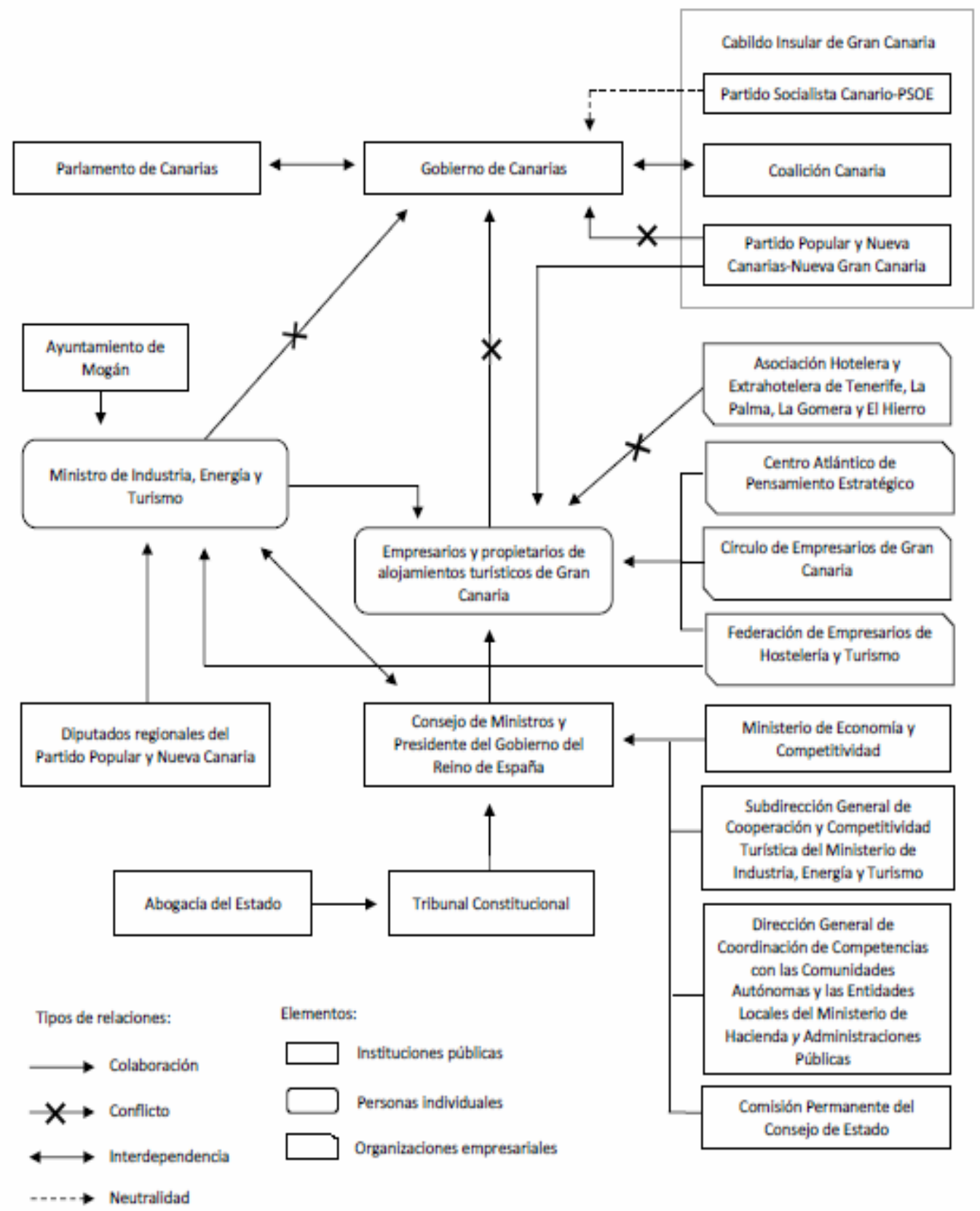


Por último, la gobernanza se ha consolidado mediante la participación y relaciones de grupos de poder económico con el Gobierno. La contestación de los actores "perdedores" reconfiguró el escenario local de gobernanza y las formas de territorialidad, así como generó nuevos esquemas de interacción entre los actores públicos y privados. Desde este punto de vista, hemos comprobado como el impacto sobre el proceso de gobernanza está relacionado con la escala del conflicto, la movilización de los actores, así como su capacidad por tomar parte en las decisiones que les competen en función tanto de sus intereses y expectativas, como de su fuerza, influencia y autoridad. En este caso, los actores "más débiles" no se mantuvieron impotentes o pasivos, sino que, por el contrario, dispusieron de cierto poder para actuar, con el fin de defender sus intereses, modificando el discurso político.

\section{Bibliografía}

Aas, C., Ladkin, A. y Fletcher, J. (2005): Stakeholder collaboration and heritage management. Annals of Tourism Research, 32 (1), 28-48.

Antón, S. (2011): Dinámicas de reestructuración de los destinos turísticos litorales del mediterráneo. Perspectivas y condicionantes. En López, D. (ed.): Renovación de destinos turísticos consolidados. XIII Congreso Internacional de Turismo Universidad y Empresa. Valencia, Tirant lo Blanch, 15-40.

Baggio, R. Scott, N. Cooper, C. (2011): Design of Tourism Governance Networks. En Laws, E., Richins, H., Agrusa, J. y Scott, N. (ed.): Tourist Destination Governance: Practice, Theory and Issues. CABI International, 159-172.

Bassols, M. (2011): Gobernanza: una mirada desde el poder. En M. Bassols y C. Mendoza (coords.) Gobernanza: teoría y practicas colectivas. Barcelona: Anthropos - UAM Iztapalapa, 7-35.

Beaumont, N. y Dredge, D. (2010): Local tourism governance: a comparison of three network approaches. Journal of Sustainable Tourism, volumen 18, 1, 7-28.

Beritelli, P. (2011): Cooperation among prominent actors in a tourist destination. Annals of Tourism Research, volume 38, 2, 607-629.

Bornhorst, T., Ritchie, J.R. y Sheehan, L. (2010): Determinants of tourism success for DMOs \& destinations: an empirical examination of stakeholders' perspective. Tourism Management, 31(5), 572-589.

Bramwell, B. (2011): Governance, the state and sustainable tourism: a political economy approach. Journal of Sustainable Tourism, 19 (4-5), 459-477.

Bramwell, B. y Lane, B. (2011): Critical research on the governance of tourism and sustainability. Journal of Sustainable Tourism, 19, 411-421.

Byrd, E.T. (2007): Stakeholders in sustainable tourism development and their roles: applying stakeholder theory to sustainable tourism development. Tourism Review, 62(2), 6-13.

Caffyn, A. \& Jobbins, G. (2003). Governance capacity and stakeholder interactions in the development and management of coastal tourism: Examples from Morocco and Tunisia. Journal of Sustainable Tourism, 11(2), 224-245. 
De Araujo, L.M. and Bramwell, B. (1999): Stakeholder assessment and collaborative tourism planning: The case of Brazil's Costa Dourada project. Journal of Sustainable Tourism, 7 (3-4), 356-378.

Domínguez Anadón, J. y Muñoz Sosa, C. (2012): II Informe CAPTPE sobre el Planeamiento y la Gestión Racional del Territorio en Canarias. Aportaciones al Anteproyecto de la futura Ley de Armonización y Simplificación en Materia de Protección del Territorio y de los Recursos Naturales. Las Palmas de Gran Canaria, Centro Atlántico del Pensamiento Estratégico.

Dredge, D. \& Pforr, C. (2008): Policy networks and tourism governance. En N Scott, N., Baggio, R. y Cooper, C. (eds): Network analysis and tourism: from theory to practice, Channel View Publications, Clevedon, 58-78.

Dredge, D. (2006): Policy networks and the local organisation of tourism. Tourism Management, volume 27, 2, 269-280.

Duran, C. (2013): Gobernanza para el sector turismo y su medición, Programa de Estadísticas y CST de la OMT Serie de Documentos Temáticos STSA/IP/2013/01.

Farinós, J. (2008): Gobernanza territorial para el desarrollo sostenible: estado de la Cuestión y Agenda”. Boletín de la Asociación de Geógrafos Españoles, 46, 11-32.

Farinós, J. (2014): Evaluación de políticas y dación de cuentas, requisitos para una adecuada gobernabilidad territorial a partir de una nueva planificación, combinando política y geografía. Perspectiva Geográfica, volumen 20, 2.

Farinós, J.; Romero, J. y Sánchez De Madariaga, I. (2005): Structural problems for the renewal of planning styles: The case of Spain. En Janin, U. y Faludi, A. (Eds.): Southern Perspectives on European Planning Special Issue. European Planning Studies, 13(2), 217 235.

Francisco, J.C. (2003): Canarias, Moratoria y REF. Santa Cruz de Tenerife, Ecopress Comunicaciones, Colección Canarias.

Hall, M. (1999): Rethinking Collaboration and Partnership: A Public Policy Perspective. Journal of sustainable tourism, vol. 7, 3 y 4, 274-289.

Hall, M. (2011): A tipology of governance and its implications for tourism policy analysis. Journal of Sustainable Tourism, 19, 437-457.

Hirschman A.O., (1970): Exit, Voice and Loyalty - Responses to decline in firms, organizations and states. Cambridge (MA), Harvard University Press.

Jamal, T. y Getz, D. (1995): Collaboration theory and community tourism planning. Annals of Tourism Research, 22 (1), 186-204.

Jamal, T. y Getz, D. (1999): Community roundtables for tourism-related conflicts: the dialectics of consensus and process structures. Journal of Sustainable Tourism, 7 (3-4), 290-313.

Krutwaysho, O. y Bramwell, B. (2010): Tourism policy implementation and society. Annals of Tourism Research, 37, 670-691.

Ledesma, O. (2016): "La gobernanza como reto para la renovación de los destinos turísticos del litoral", en Santana, A. (coord.): Tiempos de Cambio en el Turismo. Asociación Española de Expertos Científicos en Turismo (AECIT), Adeje (Tenerife), 21-26.

Lukes, S. (1985): El poder. Un enfoque radical. Madrid, Siglo XXI Editores. 
Massey, D. (2009). Concepts of space and power in theory and in political practice. Documents d'Anàlisi Geogràfica, 55, 15-26.

Massey, Doreen (1994): Space, place and gender, Minneapolis, University of Minnesota Press.

Merinero, R. y Pulido, J.I. (2009). Desarrollo turístico y dinámica relacional. Metodología de análisis para la gestión activa de destinos turísticos. Cuadernos de Turismo, 23, 173-193.

Mitchell, R. E., Agle, B. y Wood, D. (1997): Towards a theory of stakeholder identification: Defining the principle of who and what really counts. Academy of management Review, 22 (4), 853-886.

Queiroz, F. y Rastrollo-Horrillo, $\mathrm{M}^{\mathrm{a}}$ (2015): El estado del arte en gobernanza de destinos turísticos. Tourism \& Management Studies, 11(2), 47-55.

Reed, M. (1997): Power Relations and Community-Based Tourism Planning. Annals of Tourism Research, 24 (3), 556-591.

Reed, M.G. (1999): Collaborative tourism planning as adaptive experiments in emergent tourism settings. Journal of Sustainable Tourism, 7 (3-4), 331-355.

Richins, H. Agrusa, J. Scott, N. Laws, E (2011): Tourist destination governance challenges and concerns: questions of development, community involvement, responsiveness and future outcomes. En Laws, E., Richins, H., Agrusa, J. y Scott, N. (ed.): Tourist Destination Governance: Practice, Theory and Issues. CABI International, 17-23.

Robinson, M. (1999): Collaboration and cultural consent: Refocusing sustainable tourism. Journal of Sustainable Tourism, 7 (3-4), 379-397.

Rojo, A. (2005): La gobernanza: un modelo alternativo de gestionar el conflicto". Revista de pensamento do Eixo Atlantico, 8, 5-30.

Romero, J. (2009): Geopolítica y gobierno del territorio en España. Valencia, Tirant Lo Blanch.

Romero, J. y Farinós, J. (2011): Redescubriendo la gobernanza más allá del buen gobierno. Democracia como base, desarrollo territorial como resultado. Boletín de la Asociación de Geógrafos Españoles, 56, 295-319.

Ruhanen, L., Scott, N., Ritchie, B. \& Tkaczynski, A. (2010). Governance: a review and synthesis of the literature. Tourism Review, 65(4), 4-16.

Santos Chinea, M. C.; Simancas Cruz, M. R. y Hernández Martín, R. (2013): Incentivos económicos a la renovación de alojamientos turísticos: el mercado de derechos materializables en plazas alojativas. Cuadernos de Estudios Empresariales, 23, 11-26.

Sautter, E.T. y Leisen, B. (1999): Managing stakeholders a Tourism Planning Model. Annals of Tourism Research, 26 (2), 312-328.

Scott, N. Laws, E. Agrusa, J. Richins, H. (2011): Tourist destination governance: some approaches and suggestions for future research. En Laws, E., Richins, H., Agrusa, J. y Scott, N. (ed.): Tourist Destination Governance: Practice, Theory and Issues. CABI International.

Selin, S. and Chavez, D. (1995): Developing and evolutionary tourism partnershipmodel. Annals of Tourism Research, 22 (4), 844-856.

Selin, S. y Chavez, D. (1995): Developing an Evolutionary Tourism Partnership Model. Annals of Tourism Research, 22 (4), 844-856. 
Simancas Cruz, M. (2015): La moratoria turística de Canarias. La reconversión de un destino maduro desde la Ordenación del Territorio. San Cristóbal de La Laguna, Servicio de Publicaciones de la Universidad de La Laguna.

Simancas Cruz, M. (2016): Los procesos de residencialización de las áreas turísticas de litoral. En Simancas Cruz, M. y Mañoso Valderrama, J. (coords.): La residencialización de las áreas turísticas de Canarias. Promotur Turismo Canarias, S.A. / Universidad Internacional Menéndez y Pelayo. Santa Cruz de Tenerife, pp. 13-38.

Simancas Cruz, M. R. y Ledesma González, O. (2016): La planificación territorial de la política de renovación de las áreas turísticas maduras: los Planes de Modernización, Mejora e Incremento de la Competitividad de Canarias. Pasos. Revista de Turismo y Patrimonio Cultural, 14(2), 335-352.

Stamm, Caroline y Aliste, Enrique (2014): El aporte de un enfoque territorial al estudio de los conflictos socio-ambientales. Revista F@ro, vol. 2, 20, 66-78.

Timothy, D.J. (2007): Empowerment and stakeholder participation in tourism destination communities. En A. Church and T. Coles (eds): Tourism, Power and Space, London and New York: Routledge. 199-216.

Vázquez Ceballos, C. (2014): Gobernanza y redes de política pública: un estudio de la vinculación entre gobierno, actores público-sociales y privados en un área local turística. Revista Mexicana de Análisis Político y Administración Pública, volumen III, 1, 147-178.

Velasco, $\mathrm{M}^{\mathrm{a}}$ (2010): El papel del conocimiento en los nuevos modelos de gobernanza turística regional y local". En Antón, S. (Ed.): Conocimiento, creatividad y tecnología para un turismo sostenible y competitivo. Tarragona, Asociación Española de Expertos Científicos en Turismo, 131-140.

Velasco, Ma (2014): Gobernanza turística: ¿políticas públicas innovadoras o retórica banal? Cuaderno Virtual de Turismo, vol. 14, 9-22.

Velasco, $\mathrm{M}^{\mathrm{a}}$ (2016): Entre el poder y la racionalidad: gobierno del turismo, política turística, planificación turística y gestión pública del turismo. Pasos. Revista de Turismo y Patrimonio Cultural, vol. 14, 3, 577-594.

Vera, J. F. et al. (coords.) (2013): Análisis Territorial del turismo y planificación de destinos turísticos. Valencia, Tirant Humanidades. 